Enhancement of spont aneous pol ar $i$ zat $i$ on in l ead zirconate titanate thin films by Dy3+ subst $i$ t ut $i$ on

\begin{tabular}{|c|c|}
\hline 著者 & $\begin{array}{l}\text { Nakaki H r oshi, Uchi da H r oshi, Koda } \\
\text { Sei i chi r o, Okanmot o Shoj i, Funakubo H r oshi, } \\
\text { N shi da Ken, Kat oda Takashi, Sai to Kei suke }\end{array}$ \\
\hline $\begin{array}{l}\text { jour nal or } \\
\text { publ } \mathrm{i} \text { cat } \mathrm{i} \text { on } \mathrm{titl} \text { e }\end{array}$ & Appl i ed Physi cs Letters \\
\hline vol une & 87 \\
\hline number & 18 \\
\hline page $r$ ange & 182906 \\
\hline year & $2005-10-26$ \\
\hline URL & ht t p: //hdl . handl e. net /10173/794 \\
\hline
\end{tabular}




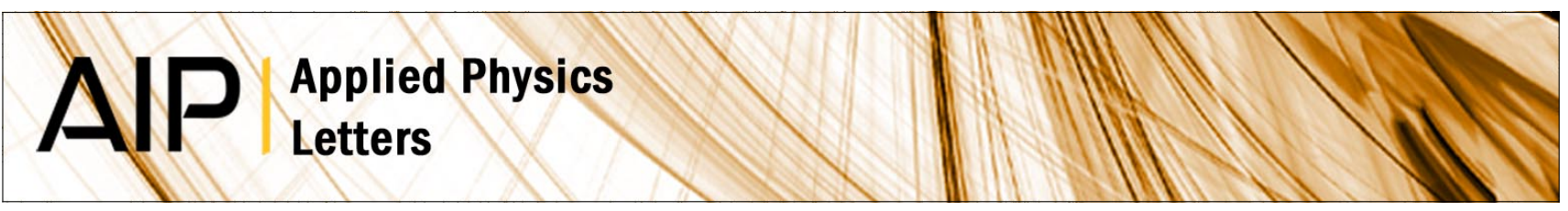

\section{Enhancement of spontaneous polarization in lead zirconate titanate thin films by Dy3+ substitution}

Hiroshi Nakaki, Hiroshi Uchida, Seiichiro Koda, Shoji Okamoto, Hiroshi Funakubo et al.

Citation: Appl. Phys. Lett. 87, 182906 (2005); doi: 10.1063/1.2125123

View online: http://dx.doi.org/10.1063/1.2125123

View Table of Contents: http://apl.aip.org/resource/1/APPLAB/v87/i18

Published by the American Institute of Physics.

Additional information on Appl. Phys. Lett.

Journal Homepage: http://apl.aip.org/

Journal Information: http://apl.aip.org/about/about_the_journal

Top downloads: http://apl.aip.org/features/most_downloaded

Information for Authors: http://apl.aip.org/authors

\section{ADVERTISEMENT}

NEW!

iPeerReview

AIP's Newest App
Authors...

Reviewers...

Check the status of

submitted papers remotely!

ADPublishing 


\title{
Enhancement of spontaneous polarization in lead zirconate titanate thin films by $\mathrm{Dy}^{3+}$ substitution
}

\author{
Hiroshi Nakaki \\ Department of Chemistry, Sophia University, Tokyo 102-8554, Japan and Department of Innovative and \\ Engineered Material, Tokyo Institute of Technology, Yokohama 226-8503, Japan \\ Hiroshi Uchida and Seiichiro Koda \\ Department of Chemistry, Sophia University, Tokyo 102-8554, Japan \\ Shoji Okamoto and Hiroshi Funakubo ${ }^{\text {a) }}$ \\ Department of Innovative and Engineered Material, Tokyo Institute of Technology, Yokohama 226-8503, \\ Japan \\ Ken Nishida and Takashi Katoda \\ Department of Electronic and Photonic Systems Engineering, Kochi University of Technology, Tosayamada- \\ cho, Kochi 782-8502, Japan \\ Keisuke Saito \\ Applocation Laboratory, Bruker AXS, 3-9-A Moriyacho, Kanagawa-ku, Yokohama 221-0022, Japan
}

(Received 22 April 2005; accepted 30 August 2005; published online 26 October 2005)

Spontaneous polarization can be enhanced by increasing the crystal anisotropy of tetragonal $\mathrm{Pb}(\mathrm{Zr}, \mathrm{Ti}) \mathrm{O}_{3}$ [PZT] lattice by $\mathrm{Zr}$ and Ti-site substitution with $\mathrm{Dy}^{3+}$ cations. Spontaneous polarization $\left(P_{s}\right)$ in epitaxial film of $2 \% \mathrm{Dy}^{3+}$-substituted tetragonal $\mathrm{Pb}\left(\mathrm{Zr}_{0.40} \mathrm{Ti}_{0.60}\right) \mathrm{O}_{3}$ [Dy-PZT] was compared with that of nonsubstituted $\mathrm{Pb}\left(\mathrm{Zr}_{0.40} \mathrm{Ti}_{0.60}\right) \mathrm{O}_{3}$ [PZT] to investigate intrinsic contribution of the Dy ${ }^{3+}$ substituion to the $P_{s}$ improvement. Epitaxial thin films of PZT and Dy-PZT with (111) orientations were grown on $(111)_{\mathrm{c}} \mathrm{SrRuO}_{3} / /(111) \mathrm{Pt} / /(100) \mathrm{YSZ} / /(100) \mathrm{Si}$ substrates by chemical solution deposition. The saturated polarization values of PZT and Dy-PZT films with (111) orientation were 41 and $48 \mu \mathrm{C} / \mathrm{cm}^{2}$, respectively. The estimated $P_{s}$ values of PZT and Dy-PZT films from the saturation polarization values were 71 and $84 \mu \mathrm{C} / \mathrm{cm}^{2}$, respectively. The $P_{s}$ value of this PZT was in good agreement with previous reports. The increase in $P_{s}$ of the epitaxial Dy ${ }^{3+}$-substituted PZT film is attributed to the enhancement of the crystal anisotropy, i.e., tetragonality, of the tetragonal PZT lattice. This shows that the enhancement of the ferroelectricity of the tetragonal PZT films can be achieved by ion substitution, just as it can in $\mathrm{Bi}_{4} \mathrm{Ti}_{3} \mathrm{O}_{12}$-based film. () 2005 American Institute of Physics. [DOI: 10.1063/1.2125123]

Tetragonal lead zirconate titanate $\left[\mathrm{Pb}(\mathrm{Zr}, \mathrm{Ti}) \mathrm{O}_{3}\right](\mathrm{PZT})$ thin films have attracted much interest for nonvolatile memory (NvRAM) application and microelectromechanical systems, due to their excellent ferroelectric and piezoelectric properties, respectively. Further improvement of the ferroelectric properties of $\mathrm{Pb}(\mathrm{Zr}, \mathrm{Ti}) \mathrm{O}_{3}$-based thin films is required for the integration of high-density NvRAM to get a large sensing margin of small capacitor cells. ${ }^{1}$ Ion substitution is widely investigated to enhance the ferroelectricity of $\mathrm{Pb}(\mathrm{Zr}, \mathrm{Ti}) \mathrm{O}_{3}$ and thin films of $\mathrm{Bi}_{4} \mathrm{Ti}_{3} \mathrm{O}_{12}$-based materials. For bulk $\mathrm{Pb}(\mathrm{Zr}, \mathrm{Ti}) \mathrm{O}_{3}$, ion substitution for enhancing the polarization has been widely investigated, but the best substituent ion and an effective substitution strategy of $\mathrm{Pb}(\mathrm{Zr}, \mathrm{Ti}) \mathrm{O}_{3}$ films has not been discovered yet. ${ }^{2-5}$ In previous studies, the main idea was to have lanthanide elements such as $\mathrm{La}^{3+}$ and $\mathrm{Nd}^{3+}$ occupy $\mathrm{Pb}$ sites, or higher valence elements such as $\mathrm{Nb}^{5+}$ occupy the $\mathrm{Zr}$ and Ti sites. For example, Bolten et $a .^{3}$ reported that $\mathrm{Nd}^{3+}$-substituted tetragonal $\mathrm{Pb}(\mathrm{Zr}, \mathrm{Ti}) \mathrm{O}_{3}$ film degraded the remanent polarization $\left(P_{r}\right)$ of PZT film because it decreased the crystal anisotropy, i.e., the ratio of lattice parameter of $c$ to $a$, (c/a ratio), in $\mathrm{Pb}(\mathrm{Zr}, \mathrm{Ti}) \mathrm{O}_{3}$ crystals. On

\footnotetext{
${ }^{\text {a) }}$ Author to whom correspondence should be addressed; electronic mail: funakubo@iem.titech.ac.jp
}

the other hand, there was hardly any report on the ferroelectric properties of $\mathrm{Pb}(\mathrm{Zr}, \mathrm{Ti}) \mathrm{O}_{3}$ substituted by smaller lanthanide ions. Park et al. and Majumber et al. reported the preferred B-site occupancy of particular lanthanide elements such as $\mathrm{Gd}^{3+}, \mathrm{Dy}^{3+}$ and $\mathrm{Yb}^{3+}$ in $\mathrm{Pb}$-based perovskite $\mathrm{ABO}_{3} \cdot{ }^{6,7}$ The present authors recently revealed that the ferroelectric properties of tetragonal $\mathrm{Pb}(\mathrm{Zr}, \mathrm{Ti}) \mathrm{O}_{3}$ film can be improved by $\mathrm{Zr}$ - and Ti-site substitution by lanthanoid ions. ${ }^{8}$ In particular, $\mathrm{PbDy}_{0.02}\left(\mathrm{Zr}_{0.40} \mathrm{Ti}_{0.60}\right)_{0.99} \mathrm{O}_{3}$ was found to increase the $P_{r}$ value from 20 to $25 \mu \mathrm{C} / \mathrm{cm}^{2}$ for (111)-preferredoriented polycrystalline $\mathrm{Pb}\left(\mathrm{Zr}_{0.40} \mathrm{Ti}_{0.60}\right) \mathrm{O}_{3}$ [PZT] films prepared by chemical solution deposition (CSD). ${ }^{8}$ This improvement is due to the enhancement of the $c / a$ ratio of the tetragonal PZT. To clarify whether intrinsic ferroelectricity is enhanced by $\mathrm{Dy}^{3+}$ substitution or not, the ferroelectric properties should be investigated using epitaxial film because not only the intrinsic substitution but also the effects of extrinsic parameters, such as the film destiny, the degree of the crystallinity, and the distribution of the crystal orientation, contribute to the ferroelectricity of the polycrystalline PZT film. ${ }^{9}$ In this letter, (111)-oriented epitaxial tetragonal PZT films were grown on (111) $\mathrm{SrRuO}_{3} / /(111) \mathrm{Pt} / /(100) \mathrm{YSZ} / /$ (100)Si substrates. The (111)-orientated PZT film is suitable for estimating the spontaneous polarization $\left(P_{s}\right)$ value because there is no contribution from $90^{\circ}$ domain switching 


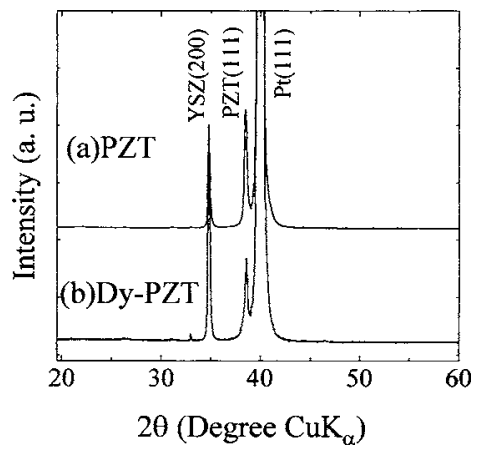

FIG. 1. XRD patterns of (a) nonsubstituted PZT and (b) Dy ${ }^{3+}$-substitution PZT films deposited on (111) $\mathrm{SrRuO}_{3} / /(111) \mathrm{Pt} / /(100) \mathrm{YSZ} / /(100) \mathrm{Si}$ substrates.

like there is for other orientations, such as $(100) /(001)$ and (110)/(101)-oriented PZT films. The $P_{s}$ values of Dysubstituted and nonsubstituted PZT were estimated using these (111)-oriented epitaxially grown films to confirm the enhancement of the $P_{s}$ value.

Epitaxial thin films with $400 \mathrm{~nm}$ in thickness were fabricated on (111) $\mathrm{SrRuO}_{3} / /(111) \mathrm{Pt} / /(100) \mathrm{YSZ} / /(100) \mathrm{Si}$ substrates (YSZ: yttria-stabilized zirconia) by CSD. The (111)oriented $\mathrm{SrRuO}_{3}$ films were grown by metalorganic chemical vapor deposition (MOCVD) on (111) Pt//(100)YSZ// (100) $\mathrm{Si}$ substrates. ${ }^{10}$ Trihydrated lead acetate $\left(\mathrm{Pb}\left(\mathrm{CH}_{3} \mathrm{COO}\right)_{2} \cdot 3 \mathrm{H}_{2} \mathrm{O}\right)$, titanium normal-butoxide $(\mathrm{Ti}(\mathrm{O} \cdot n$ $\left.\left.\mathrm{C}_{4} \mathrm{H}_{5}\right)_{4}\right)$, zirconium iso-propoxide $\left(\mathrm{Zr}\left(\mathrm{O} \cdot i-\mathrm{C}_{3} \mathrm{H}_{7}\right)_{4}\right)$, dysprosium nitrate $\mathrm{Dy}\left(\mathrm{NO}_{3}\right)_{3}$ and 2-methoxyethanol were the starting materials for the preparation of CSD precursor solutions. The nominal compositions of the precursor solutions were controlled to be $\mathrm{Pb}_{1.00}\left(\mathrm{Zr}_{0.40} \mathrm{Ti}_{0.60}\right) \mathrm{O}_{3} \quad$ [PZT] and $\mathrm{Pb}_{1.00} \mathrm{Dy}_{0.02}\left(\mathrm{Zr}_{0.40} \mathrm{Ti}_{0.60}\right)_{0.99} \mathrm{O}_{3}$ [Dy-PZT] with $5 \% \mathrm{~Pb}$ excess. The optimum Dy content was already determined to be $2 \%$ in the previous study. ${ }^{8}$ The concentration of the precursor solutions was controlled to be about $0.24 \mathrm{~mol} / \mathrm{dm}^{3}$. The solutions were spin coated at a rotation rate of $3000 \mathrm{rpm}$. A sequence comprising spin coating, drying at $150{ }^{\circ} \mathrm{C}$ for $10 \mathrm{~s}$, and pyrolysis at $400{ }^{\circ} \mathrm{C}$ for $3 \mathrm{~min}$ was performed several times to deposit a film. Finally, the samples were fired at $650{ }^{\circ} \mathrm{C}$ for $5 \mathrm{~min}$ in air for crystallization.

The constituent phase and crystal orientation of the films were confirmed by $\mathrm{x}$-ray diffraction (XRD) using a Rigaku RINT 2100 x-ray differctometer with $\mathrm{Cu} K \alpha$ radiation. Pole figure measurements of the films were performed by $\mathrm{x}$-ray diffraction (XRD) using a Philips MRD. The surface morphology and film thickness of the thin films were observed with a Hitachi S4500 scanning electron microscope together with atomic force microscopy (AFM). The polarization $(P)$ -electric field $(E)$ hysteresis curve up to $380 \mathrm{kV} / \mathrm{cm}(14 \mathrm{~V})$ was examined using a Toyo Corporation FCE ferroelectric test system. The leakage current densities were measured using a Hewlett-Packard 4155B in $0.1 \mathrm{~V}$ steps with a waiting time of $0.2 \mathrm{~s}$ between each step. To evaluate the ferroelectric properties, circular Au top electrodes with a diameter of about $\sim 500 \mu \mathrm{m}$ were deposited by vacuum evaporation deposition through a metal mask.

Ions of $2 \% \mathrm{Dy}^{3+}$ were confirmed to occupy the $\mathrm{Zr}$ and $\mathrm{Ti}$ sites of PZT films preferentially by the Raman measurement. ${ }^{11}$ Figure 1 shows $2 \theta-\omega$ XRD patterns of PZT and Dy-PZT films. Both films consisted of the tetragonal PZT perovskite phase with the preferred PZT (111) orienta-

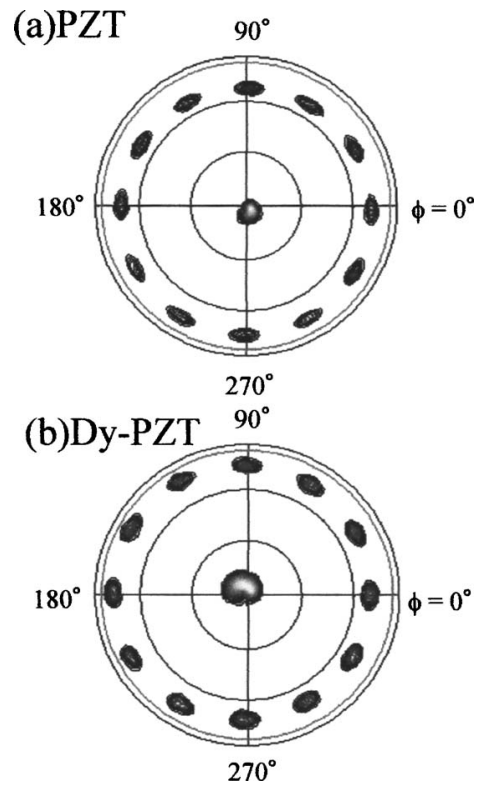

FIG. 2. X-ray pole figures measured at the fixed $2 \theta$ angel of about $38.1^{\circ}$ corresponding to PZT(111) for (a) nonsubstituted PZT and (b) $\mathrm{Dy}^{3+}$-substitution PZT films.

tion to the substrate surface. These films contained no secondary phases, such as the pyrochlore phase $\left(\mathrm{Pb}_{2} \mathrm{Ti}_{2} \mathrm{O}_{7}\right)$ or $\mathrm{Dy}_{2} \mathrm{O}_{3}$ phase.

Figures 2(a) and 2(b) show x-ray pole figures measured at the fixed $2 \theta$ angle of about $38.1^{\circ}$, which corresponds to the PZT (111) for the PZT and Dy-PZT films shown in Fig. 1. Twelve spots ascribed to the PZT(111) orientation were observed at around $\varphi=70.5^{\circ}$ together with the center one for both films. These results indicate that these films were epitaxially grown on the substrates. These spots are caused by four domains of PZT crystal with different in-plane orientations that have three symmetric rotational PZT(111) diffractions of about $\varphi=70.5^{\circ}$. The in-plane orientations of (111)PZT domains are consistent with those of (111) $\mathrm{SrRuO}_{3}$ and (111)Pt domains. ${ }^{12}$ These orientations due to the epitaxial growth of (111)PZT on each (111) $\mathrm{SrRuO}_{3}$ have been already discussed in previous work. ${ }^{10,12}$ These results confirm the epitaxial growth of PZT films on the substrates by CSD as well as by MOCVD., ${ }^{9,12}$ Obvious grain structure was not detected for both films and no obvious change in microstructure was detected by the AFM observations.

Figure 3 shows $P-E$ hysterisis loops measured at a frequency of $1 \mathrm{kHz}$ for the PZT and the Dy-PZT films. Wellsaturated hysteresis loops were observed for both films. Figure 4 shows the saturation properties of $P_{r}$ and coercive field $\left(E_{c}\right)$ values for the PZT and Dy-PZT films shown in Fig. 3.

The $P_{r}$ and $E_{c}$ values abruptly increased at about $100 \mathrm{kV} / \mathrm{cm}$, and well-saturated $P_{r}$ and $E_{c}$ values were observed against the maximum electric field. The $P_{r}$ and $E_{c}$ values of the Dy-PZT film at the maximum electric field of $380 \mathrm{kV} / \mathrm{cm}$ were measured to be $40 \mu \mathrm{C} / \mathrm{cm}^{2}$ and $88 \mathrm{kV} / \mathrm{cm}$, while those of the PZT film were $35 \mu \mathrm{C} / \mathrm{cm}^{2}$ and $85 \mathrm{kV} / \mathrm{cm}$, respectively. The saturated polarization $\left(P_{\text {sat }}\right)$ values of the PZT and Dy-PZT films evaluated from tangent lines of the hysteresis loops in Fig. 3 at the maximum electric field of $380 \mathrm{kV} / \mathrm{cm}$ are 41 and $48 \mu \mathrm{C} / \mathrm{cm}^{2}$, respectively. The ratio of the $P_{\text {sat }}$ along PZT $\langle 111\rangle$ to $P_{s}$ along the polar PZT $\langle 001\rangle$ was estimated to be $57 \%$ because the polar axis 


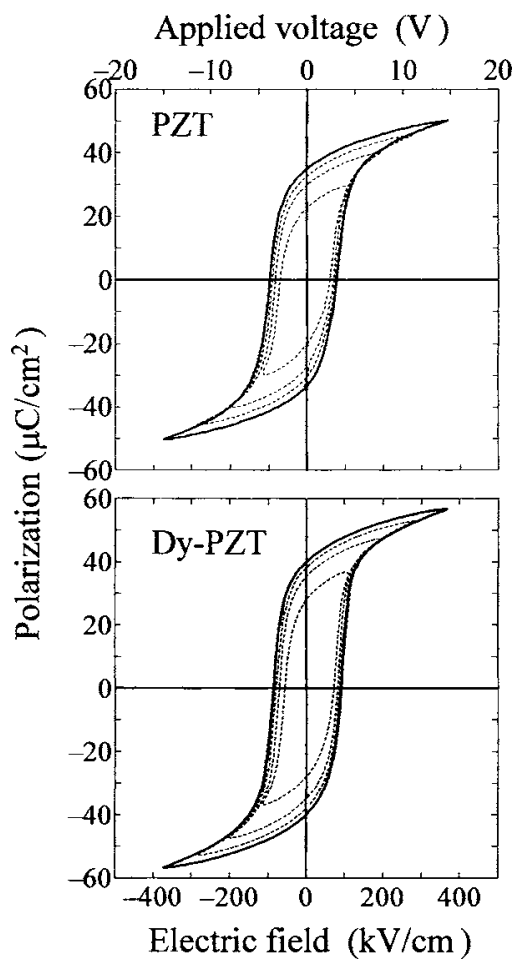

FIG. 3. $P$-E hysterisis loops measured at $1 \mathrm{kHz}$ for (a) nonsubstituted PZT and (b) Dy ${ }^{3+}$-substitution PZT films.

inclines about $55^{\circ}$ from normal of the film surface for epitaxial (111)-oriented PZT film. The extrapolation using this relationship gives $P_{s}$ values along the polar axis of 71 and $84 \mu \mathrm{C} / \mathrm{cm}^{2}$ for the PZT and Dy-PZT crystal, respectively. Using a $100 \% c$-axis-oriented epitaxial PZT film, Morioka et $a l .{ }^{13}$ estimated the $P_{s}$ values of nonsubstituted PZT crystal $(\mathrm{Zr} / \mathrm{Ti}=40 / 60)$ to be approximately $75 \mu \mathrm{C} / \mathrm{cm}^{2}$, which is consistent with the present result. ${ }^{13}$ This shows that the quality of the present epitaxially grown film prepared by CSD is sufficient for estimating the $P_{s}$ value accurately. The present results clearly show that the $P_{s}$ value of Dy-PZT film is

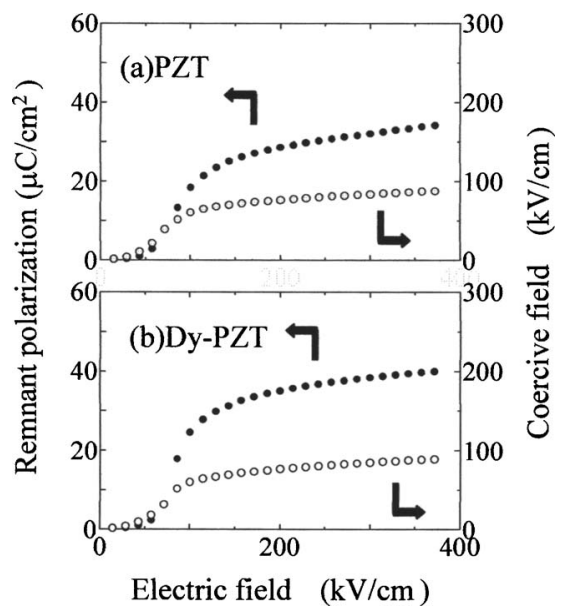

FIG. 4. Saturation properties in remanent polarization $\left(P_{r}\right)$ and coercive field $\left(E_{c}\right)$ for (a) nonsubstituted PZT and (b) Dy ${ }^{3+}$-substitution PZT films. significantly larger than that of nonsubstituted PZT.

The $c / a$ ratio of the film was estimated from PZT 200 and 002 peaks on $2 \theta-\omega$ scan at the fixed Psi angle of about $54.7^{\circ}$ corresponding to $(100) /(001)$ orientation of the film with (111) surface normal orientation. The $c / a$ ratios of PZT and Dy-PZT films at room temperature were estimated to be 1.040 and 1.046, respectively. Additionally, the Curie temperature of polycrystalline PZT and $2 \%-\mathrm{Dy}^{3+}{ }_{-}$ substituted-PZT films deposited on $\mathrm{Pt} / \mathrm{TiO}_{2} / \mathrm{SiO}_{2} /(100) \mathrm{Si}$ substrates was ascertained to be almost 410 and $430{ }^{\circ} \mathrm{C}$, respectively, by the high-temperature x-ray analysis. In PZTbased materials, increase of $T_{c}$ responds to the increase of the $c / a$ ratio of tetragonal PZT at room temperature. This $c / a$ ratio induced the increase of $P_{s}$ as Morioka $e t$ al. pointed out. ${ }^{13}$ The increase of the present $c / a$ ratio by $2 \%$ Dy substitution can be estimated to be response to the $7 \mu \mathrm{C} / \mathrm{cm}^{2}$ increase in $P_{s}$ based on the equation proposed by Morioka $e t$ al. for tetragonal PZT film. ${ }^{13}$ The present result demonstrates that the ferroelecticity of tetragonal PZT films is enhanced by ion substitution, just as it is in Nd-substituted $\mathrm{Bi}_{4} \mathrm{Ti}_{3} \mathrm{O}_{12}$-based films. ${ }^{14}$

In summary, $P_{s}$ values of nonsubstituted PZT and DyPZT were estimated using the (111)-oriented epitaxial thin films grown on (111) $\mathrm{SrRuO}_{3} / /(111) \mathrm{Pt} / /(100) \mathrm{YSZ} / /$ (100)Si substrates by chemical solution deposition. These films had crystal orientation of (111) PZT and were epitaxially grown on the substrates. The $P_{\text {sat }}$ values of the PZT and Dy-PZT films were $41 \mu \mathrm{C} / \mathrm{cm}^{2}$ and 48 , respectively. The $P_{s}$ value estimated from these $P_{\text {sat }}$ of Dy-PZT film was $84 \mu \mathrm{C} / \mathrm{cm}^{2}$, which is significantly larger than that of nonsubstituted PZT $\left(71 \mu \mathrm{C} / \mathrm{cm}^{2}\right)$. The polarization enhancement in PZT film due to the increase of crystal anisotropy was achieved by the $\mathrm{Dy}^{3+}$ substitution.

${ }^{1}$ J. F. Scott and C. A. P. de Araujo, Science 246, 1400 (1989).

${ }^{2}$ S. Majumder, B. Roy, R. Katiyar, and S. Krupandhi, Appl. Phys. Lett. 79, 239 (2001).

${ }^{3}$ D. Bolten, U. Bottger, T. Schneller, M. Grossmann, O. Lohse, and R. Waser, Integr. Ferroelectr. 32, 93 (2001).

${ }^{4}$ C. Barlingay and S. Day, Appl. Phys. Lett. 61, 1278 (1992).

${ }^{5}$ S. Yoon, H. Kang, S. Kucheike, H. Kim, and H. Jung, J. Am. Ceram. Soc. 81, 2473 (1998).

${ }^{6}$ H. B. Park, C. Y. Park, Y. S. Hong, K. Kim, and S. J. Kim, J. Am. Ceram. Soc. 82, 94 (1999).

${ }^{7}$ S. B. Majumder, P. S. Dobal, B. Roy, S. Bhasker, and R. S. Katiyar, Ferroelectr., Lett. Sect. 28, 85 (2001).

${ }^{8}$ H. Nakaki, H. Uchida, S. Yokoyama, H. Funakubo, and S. Koda, Jpn. J. Appl. Phys., Part 1 43, 6558 (2004).

${ }^{9}$ C. Foster, G. Bai, R. Csencsits, J. Vetrone, R. Jammy, L. Wills, E. Carr, and J. Amano, J. Appl. Phys. 81, 2349 (1997).

${ }^{10}$ S. Okamoto, T. Watanabe, K. Akiyama, S. Kaneko, H. Funakubo, and S. Horita, Jpn. J. Appl. Phys., Part 1, 44, 5102 (2005).

${ }^{11}$ H. Nakaki, H. Uchida, K. Nishida, M. Osada, H. Funakubo, T. Katoda, and S. Koda, Jpn. J. Appl. Phys., Part 1 44, 6905 (2005).

${ }^{12}$ Y. Kim, H. Morioka, S. Okamoto, T. Watanabe, S. Yokoyama, A. Sumi, H. Funakubo, and K. Saito, Appl. Phys. Lett. 86, 212905 (2005).

${ }^{13}$ H. Morioka, S. Yokoyama, T. Oikawa, and H. Funakubo, Appl. Phys. Lett. 85, 3516 (2004).

${ }^{14}$ T. Kojima, T. Sakai, T. Watanabe, K. Saito, M. Osada, and H. Funakubo, Appl. Phys. Lett. 80, 2746 (2002). 